CASE REPORT

\title{
Clopidogrel induced urticarial rash in a patient with left main stem percutaneous coronary intervention: management issues
}

\author{
S K Khambekar, J Kovac, A H Gershlick
}

Heart 2004;90:el 4 (http://www.heartjnl.com/cgi/contents/full/90/3/el4). doi: 10.1136/hrt.2003.027367

Clopidogrel, an ideal treatment for prevention of subacute stent thrombosis, may not be feasible to use in every patient. Ticlopidine (plus aspirin) is a very good alternative, although the risks of life threatening neutropenia should mandate regular monitoring of blood counts. It is proposed that patients undergoing angioplasty and stenting should carry a warning card in an effort to make the public and general practitioners aware that antiplatelet treatment after angioplasty plays an important part in ensuring successful outcome.

$\mathrm{P}$ ercutaneous coronary angioplasty has become the dominant mode of treatment for atheromatous obstructive coronary artery disease. Since 1977, improvement in operator expertise, equipment, and adjunctive pharmacological treatment has made it possible to treat complex coronary artery disease, including left main stem lesions. Although stents reduce the incidence of restenosis, they are associated with the risk of acute and subacute stent thrombosis by virtue of the presence of thrombogenic metal. Over the past decade, several anticoagulant and antiplatelet regimens have been tested to reduce stent thrombosis without increasing bleeding and puncture site complications.

Clopidogrel and aspirin constitute the current ideal antiplatelet regimen during coronary artery stenting. However, it is not always possible to use this combination, particularly for patients who become allergic to clopidogrel. Here we present case of a patient who underwent angioplasty to the left main stem with a drug eluting stent and shortly afterwards developed clopidogrel allergy. The case highlights the management issues.

\section{CASE REPORT}

A 68 year old woman with known ischaemic heart disease and previous coronary artery bypass grafting in 1990 (saphenous vein graft to left anterior descending coronary and circumflex arteries) developed recurrence of her angina 11 years later. Risk factors were non-insulin dependent diabetes mellitus, hypertension, hypercholesterolaemia, history of smoking, previous infarct in 1990, and a positive family history. A repeat angiogram after her admission for an episode of unstable angina showed distal $90 \%$ stenosis of the left main stem, with the left anterior descending artery occluded after the first diagonal and a $75 \%$ proximal circumflex lesion. The right coronary artery was mildly diseased. The vein graft to the left anterior descending artery was patent but that to the circumflex was occluded. In June 2003 she underwent elective angioplasty to the left main stem. The lesion was predilated and stented with two nonoverlapping drug (paclitaxel) eluting stents (fig l). She was pretreated with clopidogrel $300 \mathrm{mg}$ and advised to continue $75 \mathrm{mg}$ daily for a minimum of six months. Three weeks after the procedure she developed severe itching of both her palms followed by an urticarial rash all over her body and swelling of her lower lip (fig 2).

Her general practitioner stopped the clopidogrel and treated her with antihistaminic and oral steroids for five days. The rash gradually disappeared over two weeks. Four days after the drug was stopped the patient telephoned, anxious about the discontinuation, having been told the drug was important. We admitted the patient, initiated subcutaneous enoxaparin ( $1 \mathrm{mg} / \mathrm{kg}$ body weight) twice daily and then four days later started administration of ticlopidine $250 \mathrm{mg}$ twice a day. She has had no problems with ticlopidine and is being followed up regularly with weekly blood counts.

\section{DISCUSSION}

Acute and subacute stent thrombosis, although rare, can have serious consequences with $50 \%$ of patients sustaining a significant infarct. For some patients it is fatal. As a result the role of an antiplatelet regimen after angioplasty cannot be understated.

Initial attempts to prevent stent thrombosis with heparin and oral anticoagulant were associated with high haemorrhagic and vascular access site complications. ${ }^{1}$ FANTASTIC (full anticoagulation versus aspirin and ticlopidine trial), MATTIS (multicenter aspirin and ticlopidine trial after intracoronary stenting), and STARS (stent antithrombotic regimen study) showed that the combination of aspirin and ticlopidine was superior in preventing subacute stent occlusion and led to fewer haemorrhagic or peripheral complications than a conventional regimen combining oral anticoagulation with aspirin. ${ }^{2-4}$ However ticlopidine was associated with potential haematological toxicity $(2-2.5 \%$ rate of neutropenia and thrombotic thrombocytopaenic purpura)..$^{5}$

Clopidogrel, a new thienopyridine derivative with similar mechanism of action, had a more potent platelet antiaggregant effect than ticlopidine, a faster onset of action, and a safety profile at least as good as that of aspirin with the incidence of neutropenia $(0.1 \%)$ not more than in patients taking aspirin ${ }^{67}$ CLASSICS (clopidogrel aspirin stent international cooperative study) was the first randomised double

Abbreviations: ATLAST, antiplatelet therapy alone versus lovenox plus antiplatelet therapy in patients at increased risk of stent thrombosis; CLASSICS, clopidogrel aspirin stent international cooperative study; ENTICES, enoxaparin and ticlopidine after elective stenting; FANTASTIC, full anticoagulation versus aspirin and ticlopidine trial MATTIS, multicenter aspirin and ticlopidine trial after intracoronary stenting; STARS, stent antithrombotic regimen study 


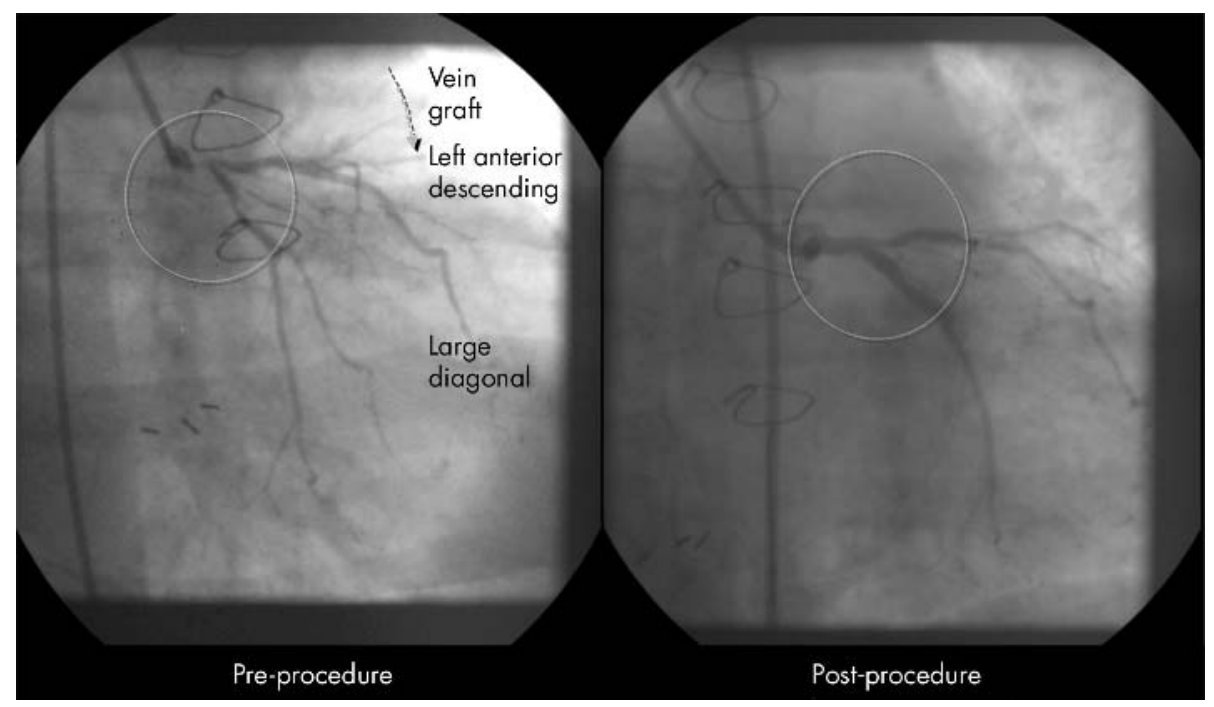

Figure 1 Before and after angioplasty

to the left main stem.

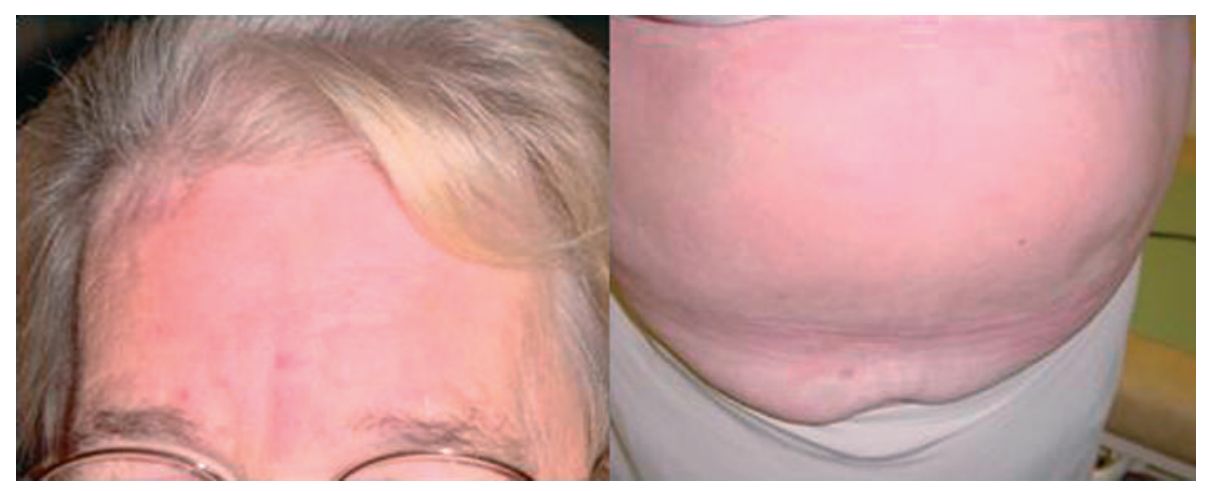

Figure 2 Clopidogrel induced urticarial rash.

blind trial to established the safety and tolerability of clopidogrel (plus aspirin) and showed efficacy to be equivalent and safety to be superior to those of ticlopidine (plus aspirin). ${ }^{8}$

Clopidogrel is now the established antiplatelet drug for preventing stent thrombosis. Even so we come across instances in clinical practice when we may have to revert to the old drugs. As in this case report, antiplatelet treatment was an important part of the angioplasty procedure, particularly with the use of drug eluting stents, which can delay re-endothelialisation, increasing the chance of late stent thrombosis.

Failure of the general practitioner to consult with the cardiologist before stopping clopidogrel raises the issue of the need to increase the awareness among primary care physicians concerning the role of antiplatelet regimens in successful outcome after coronary angioplasty. It took four days for the ticlopidine to be sent from France, during which time the patient, despite being given heparin, was at significant risk of stent closure. There may be a case therefore for stocking ticlopidine, particularly in tertiary referral centres. Deciding on the options available to treat this patient with an alternative antithrombotic regimen while awaiting the availability of ticlopidine was difficult. Here we had options of using higher dose aspirin, warfarin, or the latest anti-factor $\mathrm{X}$ agents such as bilivuridine or low molecular weight heparin. On the basis of the ENTICES (enoxaparin and ticlopidine after elective stenting) and ATLAST (antiplatelet therapy alone versus lovenox plus antiplatelet therapy in patients at increased risk of stent thrombosis) trials we decide to treat her with subcutaneous low molecular

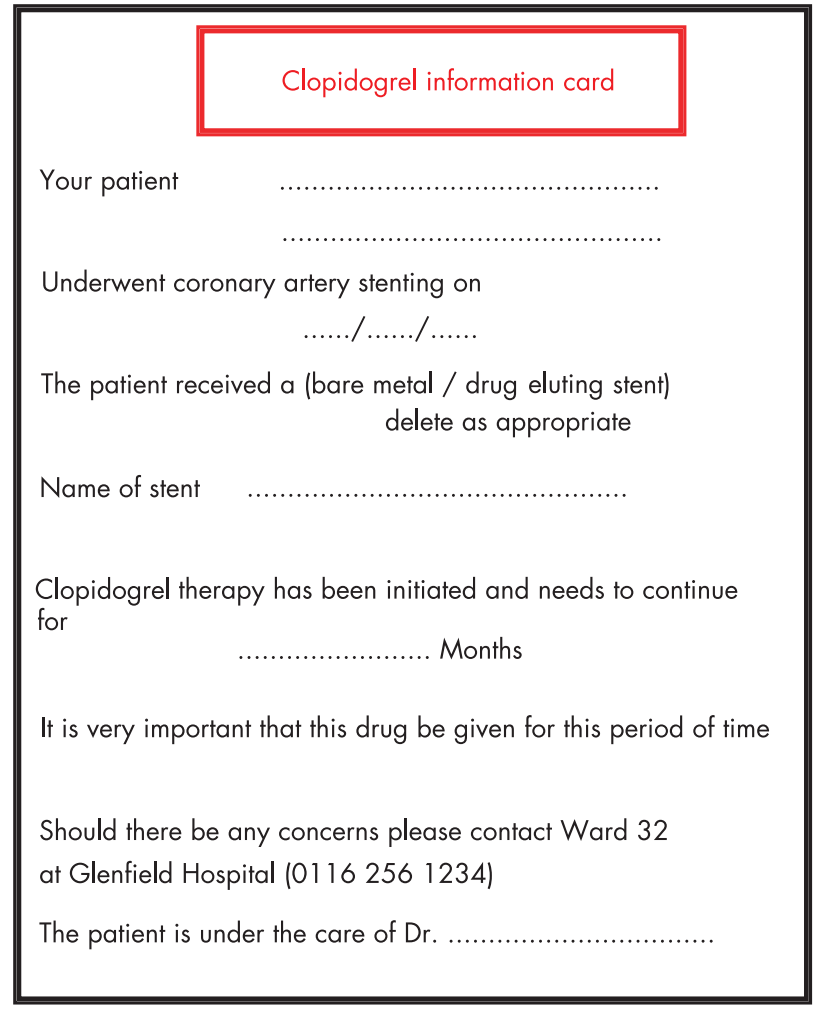

Figure 3 Clopidogrel discontinuation warning card. 
weight heparin, which would also cover for the delay in getting the ticlopidine to the hospital and the delay in onset of action of ticlopidine. ${ }^{9} 10$

\section{Conclusion}

An antiplatelet regimen has an important role in angioplasty to the left main stem. It may not be feasible to give clopidogrel, an ideal treatment for prevention of subacute stent thrombosis, to every patient. Ticlopidine (plus aspirin) is a very good alternative, although the risks of life threatening neutropenia should mandate regular monitoring of blood counts. Also we need to consider whether it is cost effective to stock ticlopidine for emergency use.

We also propose that patients undergoing angioplasty and stenting should carry a warning card (fig 3), in the same way as for endocarditis and streptokinase after thrombolysis, in an effort to make the public and general practitioners aware that antiplatelet treatment after angioplasty plays an important part in ensuring a successful outcome.

\section{Authors' affiliations}

S K Khambekar, J Kovac, A H Gershlick, Department of Cardiology, Glenfield Hospital, University Hospital of Leicester, Leicester, UK

Correspondence to: Dr S K Khambekar, Department of Cardiology, Glenfield Hospital, University Hospital of Leicester, Leicester LE3 9QP, UK; skk17@hotmail.com

Accepted 16 October 2003

\section{REFERENCES}

1 Fischman DL, Leon MB, Baim D, et al. A randomized comparison of coronary stent placement and balloon angioplasty in the treatment of coronary artery disease. N Engl J Med 1994;331:496-501.

2 Leon MB, Baim DS, Popma JJ, et al. A clinical trial comparing three antithrombotic-drug regimens after coronary-artery stenting. Stent anticoagulation restenosis study investigators. N Engl J Med 1998;339:1665-71.

3 Bertrand ME, Legrand V, Boland J, et al. Randomized multicentre comparison of conventional anticoagulation versus antiplatelet therapy in unplanned and elective coronary stenting: The full anticoagulation versus aspirin and ticlopidine (FANTASTIC) study. Circulation 1998;98:1597-603.

4 Urban P, Macaya C, Rupprecht H-J, for the MATTIS Investigators, et al. Randomized evaluation of anticoagulation versus antiplatelet therapy after coronary stent implantation in high-risk patients. Circulation 1998;98:2126-32.

5 Hall P, Nakamura S, Maiello L, et al. A randomized comparison of combined ticlopidine and aspirin therapy versus aspirin therapy alone after successful intravascular ultrasound-guided stent implantation. Circulation 1996:93:215-22.

6 Herbert JM, Frehel D, Vallee E, et al. Clopidogrel, a novel antiplatelet and antithrombotic agent. Cardiovasc Drug Rev 1993;11:180-98.

7 CAPRIE Steering Committee. A randomized blinded trial of clopidogrel versus aspirin in patients at risk of ischaemic events (CAPRIE). Lancet 1996;348:1329-39

8 Bertrand ME, Rupprecht HJ, Urban P, et al. Double-blinded study of the safety of clopidogrel with and without a loading dose in combination with aspirin compared with ticlopidine in combination with aspirin after coronary stenting (CLASSICS). Circulation 2000;102:624-9.

9 Zidar J. Low-molecular weight heparins in coronary stenting (the ENTICES trial). Am J Cardiol 1998;82:29L-32L.

10 Batchelor WB, Mahaffey KW, Berger PB, et al. A randomized, placebocontrolled trial of enoxaparin after high-risk coronary stenting: the ATLAST trial. J Am Coll Cardiol 2001 Nov 15:38:1608-13. 